\title{
Growth of Lebanese Infants in the First Year of Life
}

\author{
FAYSAL HASAN, SAMIR S. NAJJAR, ${ }^{\star}$ and RAJA Y. ASFOUR \\ From the Department of Pediatrics, the American University of Beirut, Beirut, Lebanon
}

Little published information concerning the growth characteristics of Lebanese infants is available. Woodruff (1965) noted that 80 infants receiving 'well' child care, and presumably privileged socioeconomically, had a growth pattern identical to the Iowa Growth Charts. Less privileged infants grew similarly only in the first 4 to 6 months, and subsequently their growth performance was below par. Harfouche (1966) was the first to report a longitudinal study on the height and weight of 125 Lebanese infants. These infants, however, were of families of low socioeconomic status and their growth may not represent the actual growth potential of the population. The study of infants of high socioeconomic background is probably more appropriate in this respect.

The aim of this study was to document the height and weight growth of Lebanese infants from families of a high socioeconomic status through the first year of life, and to test the suitability for Lebanese infants of a well-known growth standard based on measurements of well-born, middle western American infants of northern European stock (Jackson and Kelly, 1945), commonly referred to as the Iowa Growth Charts. These measurements have been shown recently not to have appreciably changed over a period of 30 years (Jackson et al., 1964).

\section{Material and Methods}

Three hundred and ten infants, 158 boys and 152 girls, seen by two of us (R.A. and S.N.) for 'well' baby care between 1965 and 1968 were included in this study. All were normal, healthy, full-term Lebanese infants. Their birthweight was more than $2500 \mathrm{~g}$., and they had no congenital defects and no prolonged or repeated illnesses. All belonged to families of high socioeconomic status. They were seen for paediatric care and guidance at intervals of 4 to 6 weeks in the first 6 months, and less frequently subsequently. Mothers were encouraged to breast-feed. Every infant was fed milk exclusively for 1 to 3 months, then solids such as fruits, cereals, vegetables, and egg-yolk were added

Received August 13, 1968.

Reprint requests should be sent to this author at Department of Pediatrics, The American University Hospital, Beirut, Lebanon. gradually. By 5 months meat was included. After the ninth month they were gradually introduced to 'junior' baby food and family food. Vitamins were given routinely by one author (S.N.) and on indication by another (R.A.). $72 \%$ of the males and $68 \%$ of the females were breast-fed at the age of 1 month. At the age of 6 months only $15 \%$ of the males and $21 \%$ of the females were breast-fed.

Each infant had at least three valid measurements in the first 6 months of life, with an interval of at least one month between each measurement. The measurements were performed by the paediatrician himself. The nude weight was recorded; the height was obtained by measuring the supine length, with the infant stretched maximally on a table between two fixed upright boards.

The data for each month were averaged, and the ages were rounded up to include 7 days before or after the month. Because several infants came for check-up later than 7 days after the end of the month, and because all the infants were not seen at the same interval, the number of monthly observations was not equal to the number of infants. The number of observations between the eighth and the eleventh month was small because of the infrequent visits to the paediatricians at this age.

\section{Results}

The mean length and median weight for male and female infants at various ages are shown in Tables I and II, respectively. The range of the measurements as well as the number of subjects in each age-group are also shown in these 2 Tables. These values were plotted on the Iowa Growth Chart and are shown in Figures 1 and 2 . In these we have also indicated the mean length and median weight obtained by Harfouche (1966) on Lebanese infants of families of low socioeconomic status. The mean weight and median length of the 2 groups at 3-monthly intervals are shown in Tables III and IV.

It is apparent that in both sexes the values for length and weight of infants from families of a high socioeconomic status are not different from those of North American subjects. After the age of 3 months, these infants are longer and heavier than those who have grown up in less favourable environmental circumstances. This difference is 
TABLE I

Mean Length and Median Weight of Well-nourished Lebanese Boys

\begin{tabular}{|c|c|c|c|c|c|c|}
\hline Age (mth.) & No. of Subjects & Length (cm.) & Range for Length & No. of Subjects & Weight (g.) & $\begin{array}{c}\text { Range for Weight } \\
\text { (g.) }\end{array}$ \\
\hline $\begin{array}{c}\text { Birth } \\
1 \\
2 \\
3 \\
4 \\
5 \\
6 \\
7 \\
8 \\
9 \\
10 \\
11 \\
12\end{array}$ & $\begin{array}{l}21 \\
60 \\
46 \\
56 \\
52 \\
50 \\
39 \\
38 \\
20 \\
22 \\
19 \\
13 \\
24\end{array}$ & $\begin{array}{l}50 \cdot 2 \\
54 \cdot 3 \\
58 \cdot 2 \\
61 \cdot 4 \\
64 \cdot 1 \\
66 \cdot 4 \\
68 \cdot 7 \\
70 \cdot 3 \\
71 \cdot 4 \\
72 \cdot 9 \\
75 \cdot 0 \\
75 \cdot 2 \\
75 \cdot 8\end{array}$ & $\begin{array}{c}47-54 \\
50-59 \\
54-62 \\
57-66 \\
57-68 \\
63-70 \cdot 5 \\
64-75 \\
66-75 \\
68-74 \cdot 5 \\
67 \cdot 5-75 \cdot 5 \\
72-78 \\
72-78 \\
71 \cdot 5-79\end{array}$ & $\begin{array}{r}128 \\
62 \\
53 \\
63 \\
56 \\
56 \\
42 \\
36 \\
22 \\
25 \\
19 \\
15 \\
27\end{array}$ & $\begin{array}{c}3500 \\
4400 \\
5500 \\
6450 \\
7130 \\
7750 \\
8100 \\
9000 \\
9250 \\
9800 \\
10,275 \\
10,850 \\
10,500\end{array}$ & $\begin{array}{l}2500-4500 \\
3075-5450 \\
3700-7000 \\
4450-8000 \\
5100-9600 \\
5250-10,800 \\
6300-12,000 \\
7340-11,300 \\
7900-11,350 \\
8100-12,250 \\
9000-12,500 \\
9100-13,000 \\
8700-15,500\end{array}$ \\
\hline
\end{tabular}

TABLE II

Mean Length and Median Weight of Well-nourished Lebanese Girls

\begin{tabular}{|c|c|c|c|c|c|c|}
\hline Age (mth.) & No. of Subjects & Length (cm.) & Range for Length & No. of Subjects & Weight (g.) & $\begin{array}{l}\text { Range for Weight } \\
\text { (g.) }\end{array}$ \\
\hline $\begin{array}{c}\text { Birth } \\
1 \\
2 \\
3 \\
4 \\
5 \\
6 \\
7 \\
8 \\
9 \\
10 \\
11 \\
12\end{array}$ & $\begin{array}{l}15 \\
61 \\
42 \\
64 \\
58 \\
50 \\
35 \\
18 \\
18 \\
20 \\
13 \\
10 \\
25\end{array}$ & $\begin{array}{l}49 \cdot 7 \\
53 \cdot 5 \\
57 \cdot 2 \\
60 \cdot 2 \\
62 \cdot 6 \\
64 \cdot 8 \\
66 \cdot 8 \\
68 \cdot 3 \\
69 \cdot 9 \\
70 \cdot 8 \\
73 \cdot 0 \\
74 \cdot 8 \\
75 \cdot 0\end{array}$ & $\begin{array}{c}47-53 \\
51-58 \cdot 5 \\
52-62 \\
56-64 \\
58-66 \\
60 \cdot 5-69 \\
61 \cdot 5-71 \\
63 \cdot 5-72 \cdot 5 \\
65-75 \\
67-78 \\
71-77 \\
73-78 \\
72-80\end{array}$ & $\begin{array}{r}126 \\
63 \\
43 \\
65 \\
61 \\
55 \\
38 \\
23 \\
19 \\
21 \\
14 \\
10 \\
26\end{array}$ & $\begin{array}{c}3300 \\
4200 \\
5162 \\
5825 \\
6600 \\
7025 \\
7700 \\
7800 \\
8475 \\
8500 \\
9000 \\
9900 \\
10,000\end{array}$ & $\begin{array}{l}2500-4400 \\
3100-5400 \\
4080-6600 \\
4500-7200 \\
5000-7800 \\
5700-8800 \\
5975-9500 \\
6600-9850 \\
6900-10,000 \\
7100-11,350 \\
7400-10,750 \\
8800-12,500 \\
8600-13,200\end{array}$ \\
\hline
\end{tabular}

more pronounced among females, and may represent the privileged status of males in this particular society.

The individual values for infants who were not

TABLE III

Mean Length and Median Weight of Lebanese Male Infants of High and Low Socioeconomic Background

\begin{tabular}{|c|c|c|c|c|}
\hline \multirow{2}{*}{$\begin{array}{c}\text { Age } \\
\text { (mth.) }\end{array}$} & \multicolumn{2}{|c|}{$\begin{array}{l}\text { Infants of Low } \\
\text { Socioeconomic Status } \\
\text { (Harfouche, 1966) }\end{array}$} & \multicolumn{2}{|c|}{$\begin{array}{l}\text { Infants of High } \\
\text { Socioeconomic Status }\end{array}$} \\
\hline & $\begin{array}{l}\text { Length } \\
\text { (cm.) }\end{array}$ & $\begin{array}{l}\text { Weight } \\
\text { (g.) }\end{array}$ & $\begin{array}{l}\text { Length } \\
\text { (cm.) }\end{array}$ & $\begin{array}{l}\text { Weight } \\
\text { (g.) }\end{array}$ \\
\hline $\begin{array}{c}\text { Birth } \\
1 \\
3 \\
6 \\
9 \\
12\end{array}$ & $\begin{array}{l}50 \cdot 1 \\
54 \cdot 8 \\
61 \cdot 2 \\
67 \cdot 6 \\
71 \cdot 8 \\
75 \cdot 1\end{array}$ & $\begin{array}{l}3400 \\
4390 \\
6190 \\
7880 \\
8930 \\
9810\end{array}$ & $\begin{array}{l}50 \cdot 2 \\
54 \cdot 3 \\
61 \cdot 4 \\
68 \cdot 7 \\
72 \cdot 9 \\
75 \cdot 8\end{array}$ & $\begin{array}{r}3500 \\
4400 \\
6450 \\
8100 \\
9800 \\
10,500\end{array}$ \\
\hline
\end{tabular}

*Data from present study. measured at 1 month \pm 7 days and who were not included in this study were very close to the mean and median of the length and weight of the Iowa Growth Chart.

TABLE IV

Mean Length and Median Weight of Lebanese Female Infants of High and Low Socioeconomic Background

\begin{tabular}{|c|c|c|c|c|}
\hline \multirow{2}{*}{$\begin{array}{c}\text { Age } \\
\text { (mth.) }\end{array}$} & \multicolumn{2}{|c|}{$\begin{array}{l}\text { Infants of Low } \\
\text { Socioeconomic Status } \\
\text { (Harfouche, 1966) }\end{array}$} & \multicolumn{2}{|c|}{$\begin{array}{l}\text { Infants of High } \\
\text { Socioeconomic Status }\end{array}$} \\
\hline & $\begin{array}{l}\text { Length } \\
\text { (cm.) }\end{array}$ & $\begin{array}{l}\text { Weight } \\
\text { (g.) }\end{array}$ & $\begin{array}{l}\text { Length } \\
\text { (cm.) }\end{array}$ & $\begin{array}{l}\text { Weight } \\
\text { (g.) }\end{array}$ \\
\hline $\begin{array}{c}\text { Birth } \\
1 \\
3 \\
6 \\
9 \\
12\end{array}$ & $\begin{array}{l}49 \cdot 5 \\
53 \cdot 9 \\
59 \cdot 6 \\
65.5 \\
69.5 \\
73 \cdot 0\end{array}$ & $\begin{array}{l}3300 \\
4110 \\
5520 \\
7130 \\
8160 \\
8940\end{array}$ & $\begin{array}{l}49 \cdot 7 \\
53 \cdot 5 \\
60 \cdot 2 \\
66 \cdot 7 \\
70 \cdot 8 \\
75 \cdot 0\end{array}$ & $\begin{array}{r}3300 \\
4200 \\
5825 \\
7700 \\
8500 \\
10,000\end{array}$ \\
\hline
\end{tabular}

^Data from present study. 


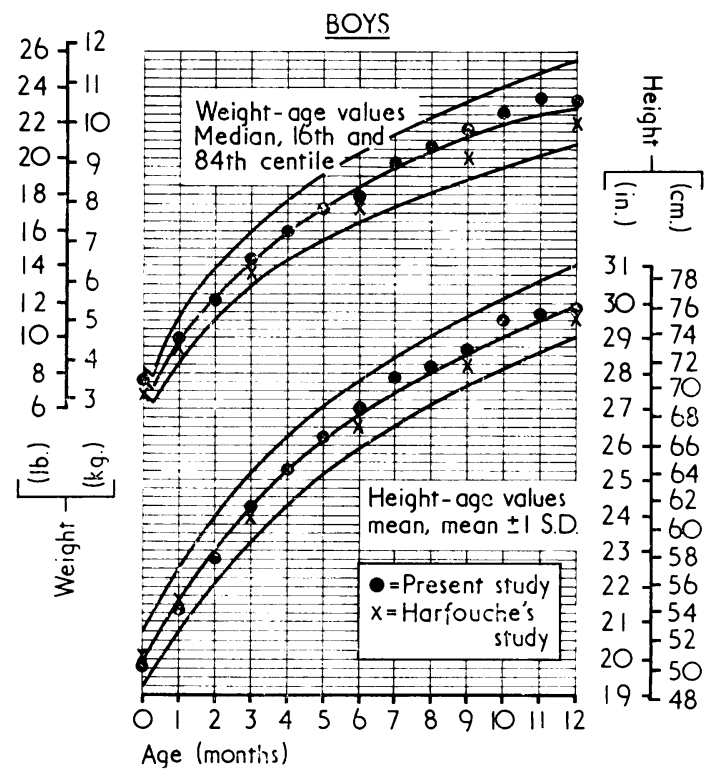

FIG. 1.-Mean length and median weight of Lebanese male infants.

\section{Discussion}

The results of our longitudinal study indicate that the use of the North American growth standards, in particular the Iowa Growth Charts, is justified for Lebanese infants in the first year of life. The performance of the socioeconomically favoured group suggests that the genetic growth potentials of Lebanese infants are similar to those of North American subjects. This observation is of special interest because of the ethnic difference between the two groups, northern European versus Arab stock.

Woodruff (1965) using a cross-sectional study of older Lebanese children and adolescents found that the growth pattern of the socioeconomically privileged was not significantly different from the Iowa Growth Standards. A longitudinal study, however, is needed to further substantiate Woodruff's observations on older children and the suitability of the Iowa Growth Charts for older Lebanese children and adolescents.

The data of Woodruff (1965) and Harfouche (1966) on the growth of infants of parents of low socioeconomic background as compared to ours demonstrate once again the adverse influence that environmental factors can have on the rate of growth. The better growth performance of the infants in Harfouche's study as compared with

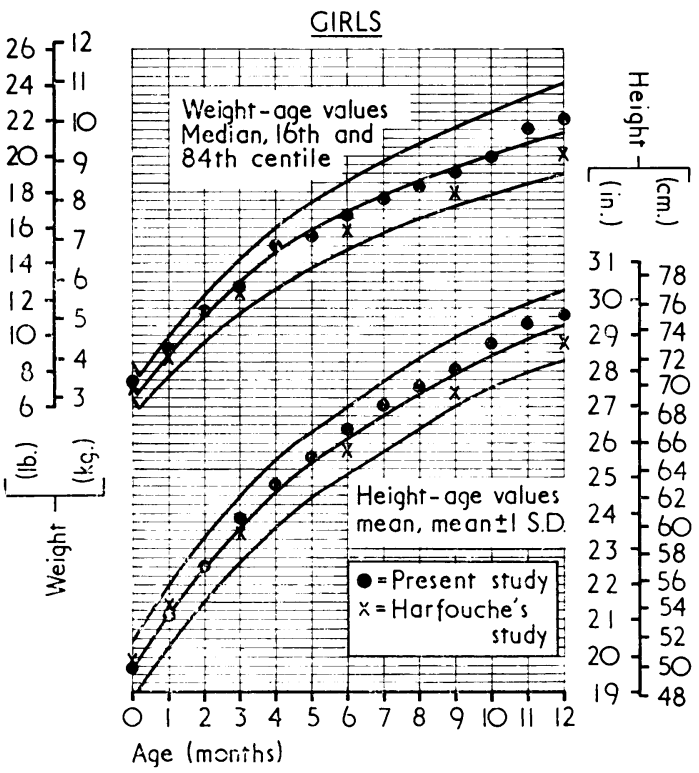

FIG. 2.-Mean length and median weight of Lebanese female infants.

those studied by Woodruff is probably a reflection of the regular medical care received by the former group in contrast to the haphazard medical care of the latter who were sick infants coming for the first time or haphazardly to an outpatient department.

\section{Summary}

The growth of 310 healthy, well-nourished Lebanese infants from an upper socioeconomic status were studied longitudinally. The data for length and weight compared favourably with the Iowa standards of growth, and were superior, after the age of 3 months, to the results obtained on a group of Lebanese infants from a lower socioeconomic background, reported by Harfouche in 1966.

\section{REFERENCES}

Harfouche, J. K. (1966). Growth and Illness Patterns of Lebanese Infants. Khayat, Beirut.

Jackson, R. L., and Kelly, H. G. (1945). Growth charts for use in pediatric practice. $\mathcal{F}$. Pediat., 27, 215.

Westerfeld, R., Flynn, M. A., Kimball, E. R., and Lewis, R. B. (1964). Growth of 'well born' American infants fed human and cow's milk. Pediatrics, 33, 642.

Woodruff, C. W. (1965). Growth and nutrition of Lebanese children. Nutr. Rev., 23, 97. 